\title{
"Implementation and Comparison of Different Switching Techniques for Shunt Active Power
} Filters"

IEEE IECON Industrial Electronics Conference, pp.1519-1525, Dallas Texas USA, Oct. 2014.

http://ieeexplore.ieee.org/stamp/stamp.jsp?tp=\&arnumber=7048811\&tag=1

ISBN: 978-1-4799-4033-2

ISSN: $1553-572 \mathrm{X}$

DOI: $10.1109 /$ IECON.2014.7048703

This material is posted here with permission of the IEEE. Such permission of the IEEE does not in any way imply IEEE endorsement of any of Group of Energy and Power Electronics, University of Minho, products or services. Internal or personal use of this material is permitted. However, permission to reprint/republish this material for advertising or promotional purposes or for creating new collective works for resale or redistribution must be obtained from the IEEE by writing to pubs-permissions@ieee.org. By choosing to view this document, you agree to all provisions of the copyright laws protecting it.

\section{(C) 2014 IEEE}




\title{
Implementation and Comparison of Different Switching Techniques for Shunt Active Power Filters
}

\author{
Ângelo Araújo, J. G. Pinto, Bruno Exposto, João L. Afonso \\ ALGORITMI Research Centre - University of Minho \\ Guimarães, Portugal \\ \{angelo.araujo | gabriel.pinto | bruno.exposto | joao.l.afonso\}@algoritmi.uminho.pt
}

\begin{abstract}
This paper presents a comparison between three switching techniques that can be used in three-phase four-wire Shunt Active Power Filters (SAPFs). The implemented switching techniques are: Periodic-Sampling (PS), Triangular Carrier Pulse-Width Modulation (TC-PWM) and Space Vector PWM (SVPWM). The comparison between them is made in terms of the compensated currents THD\%, implementation complexity, necessary CPU time and SAPF efficiency. To perform this comparison are presented and analyzed several experimental results, obtained with a $20 \mathrm{kVA}$ Shunt Active Power Filter prototype, specially developed for this purpose. The control system of the developed SAPF is based in the $p-q$ Theory with a grid synchronization algorithm $p-P L L$.
\end{abstract}

Index Terms- Shunt Active Power Filter (SAPF), Switching Techniques, Periodic Sampling (PS), Triangular Carrier PulseWidth Modulation (TC PWM), Space Vector PWM (SVPWM).

\section{INTRODUCTION}

Loads with nonlinear current-voltage characteristic such as variable-speed drives, arc furnaces, battery chargers and other electronic controlled devices drain distorted currents from the power grid. The circulation of distorted currents trough the line impedances, causes the distortion in the grid voltages. This affects other sensitive loads connected to the grid [1]. Passive filters can mitigate specific harmonics for that they are tuned but cannot adapt to new loads or new operation conditions [2]. Other drawbacks associated with capacitors used for power factor compensation and with passive filters is the occurrence of resonance problems [2].

Shunt Active Power Filters (SAPFs) consist in power electronics based equipment designed to mitigate power quality problems related with the currents, in particular harmonics, power factor and unbalances. When compared to conventional solutions SAPFs present several advantages, namely the capability of dynamically adjust to different operation conditions and the capability of simultaneously compensate the power factor and harmonics [3][4].

The power converter that is integrated in the SAPF is an inverter. Although that exist several topologies of power inverters that can be used in SPAFs, the most common adopted topology is the voltage-source inverter (VSI). This inverter is connected in parallel with the power grid through coupling inductors or transformers.

In order to produce de compensation currents the VSI converter of the SAPF must be controlled as a current source. To do this, is necessary use a current controller to determine the voltage that the converter must produce in each instant to impose the desired currents into the electrical grid [5].

To synthetize the compensation currents calculated by the SAPF control, it is also necessary use some type of switching technique. The switching technique defines in each time instant the state of semiconductors of the power inverter in way that the output current of the inverter is equal to the reference current. The choice of the appropriate switching technique is an important decision to ensure a good current tracking, low current THD and high efficiency. Given this, the study of different switching techniques for a specific application is very important. The comparison of some switching techniques has been already made by some authors [6][7]. Nevertheless, it can be made a more detailed study of the characteristics and behavior of these switching techniques.

Given this, the objective of this paper is comparing three switching techniques that can be used in Shunt Active Power Filters. The switching techniques are Periodic-Sampling (PS), Triangular Carrier PWM (TC-PWM) and Space Vector PWM (SVPWM) [8][6][9]. The techniques were implemented and was assessed the performance of the SAPF when compensating the loads currents.

The SAPF topology consists in a three-phase four-wire voltage source inverter (Fig. 1), using IGBTs as switching devices. The inverter is connected to the electrical grid through four inductors (one per phase).

The control of the SAPF and the switching techniques were

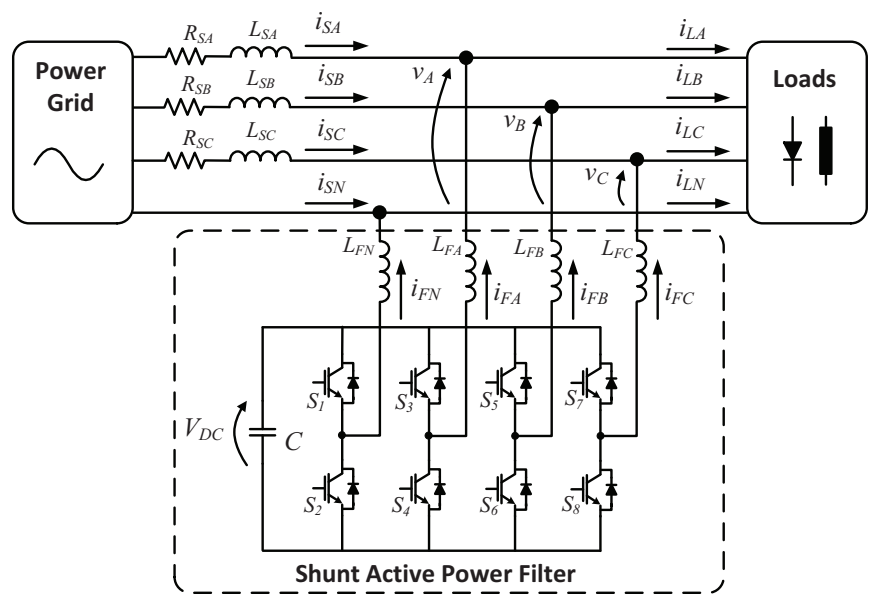

Fig. 1 Electrical system with three-phase four-wire Shunt Active Power Filter (SAPF). 
implemented using a Digital Signal Processor (DSP) TMS320F2812 from Texas Instruments.

\section{Shunt Active Power Filter CONTROL}

The control algorithm used to calculate the reference for the compensation currents is based in the Theory of the Instantaneous Reactive Power ( $p-q$ Theory), introduced by Akagi et al. [10] and expanded to three-phase four-wire systems by Aredes et al. [11]. To apply this control theory, first the measured load currents and grid voltages must be translated from the $A-B-C$ to the $\alpha-\beta-0$ reference frame by applying the Clarke-Concordia transformation (1) [11].

$$
T=\sqrt{\frac{2}{3}}\left[\begin{array}{ccc}
1 & -\frac{1}{2} & -\frac{1}{2} \\
0 & \frac{\sqrt{3}}{2} & -\frac{\sqrt{3}}{2} \\
\frac{1}{\sqrt{2}} & \frac{1}{\sqrt{2}} & \frac{1}{\sqrt{2}}
\end{array}\right]
$$

After the transformation, the instantaneous real power, $p$, the instantaneous imaginary power, $q$, and the instantaneous zero-sequence power, $p_{0}$, are calculated by (2), (3) and (4).

$$
\begin{gathered}
p=v_{\alpha} i_{\alpha}+v_{\beta} i_{\beta} \\
q=v_{\alpha} i_{\beta}+v_{\beta} i_{\alpha} \\
p_{0}=v_{0} i_{0}
\end{gathered}
$$

Each of the power defined by the $p-q$ Theory must be separated in average and oscillating parts. To accomplish with this task a sliding window average technique is used [11].

In an electrical installation with an SAPF in operation the power grid must only supply the average part of the instantaneous real power $(\bar{p})$ and the average part of the zerosequence power $\left(\bar{p}_{0}\right)$. The oscillating part of the instantaneous real power $(\tilde{p})$, the oscillating part of the zero sequence power $\left(\tilde{p}_{0}\right)$ and the instantaneous imaginary power $(q)$ don't implies any energy transference from the power grid to the load and therefore can be supplied by the SAPF.

To maintain the voltage at the DC-link capacitor $\left(V_{D C}\right)$ regulated it is necessary to absorb from the power grid an additional regulation power $\left(p_{\text {reg }}\right)$. This regulation power that in steady state operation corresponds to the power losses in the SAPF must be subtracted from the power components to be compensated as show in (5).

The reference for the compensation currents in the $\alpha-\beta-0$ reference frame are calculated by (5) and (6).

$$
\begin{gathered}
p_{x}=\tilde{p}-\bar{p}_{0}-p_{r e g} \\
{\left[\begin{array}{c}
i_{c \alpha} \\
i_{c \beta}
\end{array}\right]=\frac{1}{v_{\alpha}^{2}+v_{\beta}^{2}}\left[\begin{array}{cc}
v_{\alpha} & v_{\beta} \\
-v_{\beta} & v_{\alpha}
\end{array}\right]\left[\begin{array}{c}
p_{x} \\
q
\end{array}\right]}
\end{gathered}
$$

$$
i_{c 0}=i_{0}
$$

The references for the compensation currents in the $A-B-C$ reference frame are calculated by applying the inverse Clarke-Concordia transformation (8).

$$
T^{-1}=\sqrt{\frac{2}{3}}\left[\begin{array}{ccc}
\frac{1}{\sqrt{2}} & 1 & 0 \\
\frac{1}{\sqrt{2}} & -\frac{1}{2} & \frac{\sqrt{3}}{2} \\
\frac{1}{\sqrt{2}} & -\frac{1}{2} & -\frac{\sqrt{3}}{2}
\end{array}\right]
$$

To determine the reference for the compensating currents that impose sinusoidal currents from the source side, even with distorted grid voltages, it is necessary to use a grid synchronization algorithm like a phase-locked loop (PLL) [12][13]. The algorithm used in this work was proposed by Aredes et al. [14] and can be seen in Fig. 2. This algorithm, also known as $p-P L L$, is easy to implement and as it uses the $\alpha-\beta-0$ reference frame a post conversion is not needed. The $p$-PLL scheme reaches a stable operating point when the input $f_{p}$ of the PI regulator is zero.

\section{Shunt Active Power Filter Switching TECHNIQUES}

The switching techniques are responsible for controlling the state of the power inverter IGBTs in order to produce the current calculated by the SAPF controller. In the next topics three different approaches to the switching techniques used in the three-phase four-wire SAPFs will be presented.

\section{A. Periodic Sampling (PS)}

This switching technique is simple to implement and robust. Nevertheless has the disadvantage of not guarantee a fixed switching frequency and only can be defined a maximum switching frequency (half of the sampling frequency). In Fig. 3 (a) is shown the implementation of this switching technique. Although that in the figure is shown a D-type flip-flop, the implementation of this switching technique in the DSP only requires a simple comparison between the reference current $\left(i_{c x} *\right)$ and the inverter current, $\left(i_{c x}\right)$ acquired at constant sampling rate. The result of that comparison is used to determine the state of the switches $\left(S_{x}\right)$ (8), (9).

$$
\begin{gathered}
S_{x T}= \begin{cases}1, & i_{c x} *>i_{c x} \\
0, & i_{c x} * \leq i_{c x}\end{cases} \\
S_{x B}=! S_{x T}
\end{gathered}
$$

This is a nonlinear current control technique that blends the current control with the modulation [11].

\section{B. Triangular-Carrier PWM(TC-PWM)}

In this switching technique, the measured current $\left(i_{c x}\right)$ is compared with the reference current $\left(i_{c x} *\right)$. The output signal 


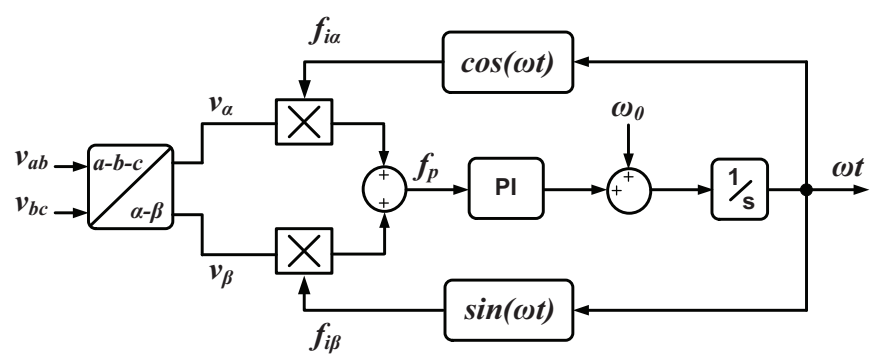

Fig. 2 Block diagram of the grid synchronization algorithm $p$-PLL.

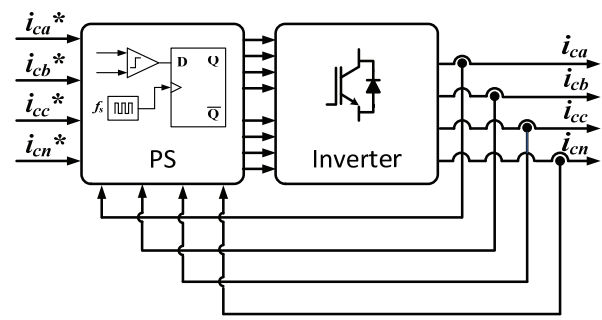

(a)

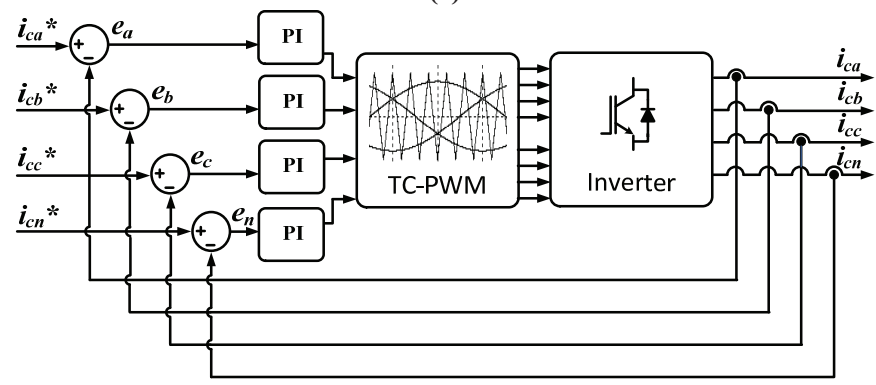

(b)

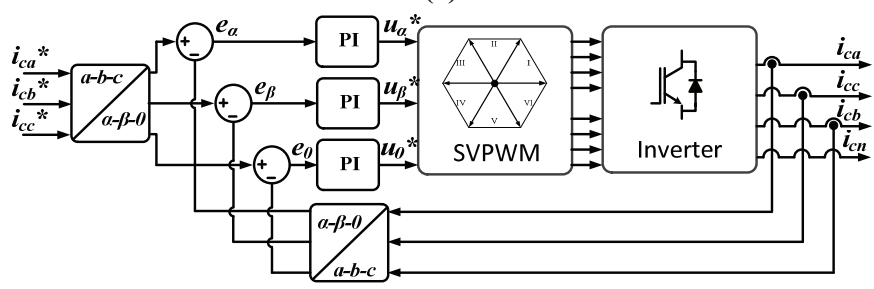

(c)

Fig. 3 Block diagram of the implemented switching technique: (a) Periodic Sampling (PS), (b) Triangular Carrier Pulse-Width Modulation (TC PWM); (c) Space Vector PWM (SVPWM).

is passed to a controller, typically a PI, and compared with a triangular carrier (Fig. 3 (b)). The gains $k_{p}$ and $k_{i}$ determine the transient response as well as the steady-state response [7]. This is a linear current control technique and the function of PI controller is to reduce the error to zero [15].

Analyzing the block diagram in (Fig. 3) is clearly visible that the TC-PWM is more complex to implement than the PS method. Especially because exist a lot of steps that must be performed to ensure that the switching technique has a good performance. This switching technique has the advantage of result in a fixed switching frequency. Nevertheless, the gains in the PI controller are difficult to adjust especially because the load in the active power filter can change [7].

\section{Space Vector PWM (SVPWM)}

In this switching technique the reference signal is compared with the output current in the $\alpha-\beta-0$ frame

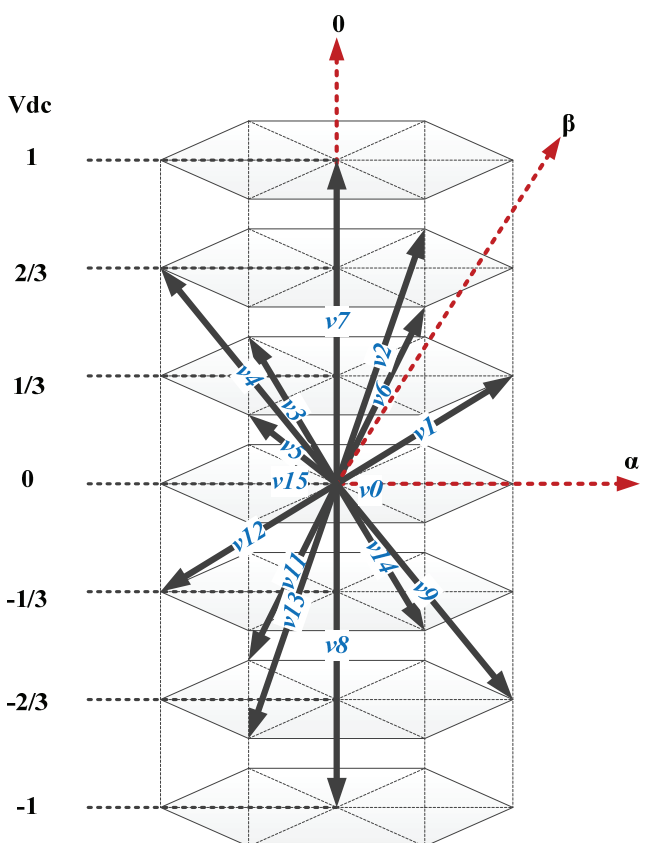

Fig. 4 Representation of the switching vectors of the power inverter in the $\alpha-\beta-0$ reference frame.

(Fig. 3 (c)). With this comparison are obtained three errors $\left(e_{\alpha}, e_{\beta}\right.$ and $\left.e_{0}\right)$. The errors $e_{\alpha}, e_{\beta}$ and $e_{0}$ are the input of two PI controllers. The outputs of the two PI controllers are then used to determine which vector must be used in the $\alpha-\beta-0$ frame. Fig. 4 shows the $\alpha-\beta-0$ frame and the vectors associated with the states of the inverter [16].

The determination of the reference vector location is done in two steps. First is necessary locate in which prism is located, and then in which tetrahedron. To know in which prism the reference vector is located, are used expressions (11), (12) and (13) [16].

$$
\begin{gathered}
\gamma_{1}=e_{\beta} \\
\gamma_{2}=-\frac{1}{2} e_{\beta}+\frac{\sqrt{3}}{2} e_{\alpha} \\
\gamma_{3}=-\frac{1}{2} e_{\beta}-\frac{\sqrt{3}}{2} e_{\alpha}
\end{gathered}
$$

After this is necessary locate the prism in which the vector is located. To perform this task in a simple way, can be used (14). The variable $\Psi_{x}$ takes the value ' 1 ' if $\gamma_{x}$ is positive and the value ' 0 ' if $\gamma_{x}$ is negative.

$$
\Theta=\Psi_{1}+2 \Psi_{2}+4 \Psi_{3}
$$

With the prism determined is now possible to know the tetrahedron in which the reference vector is located. For that is used (15).

$$
\Lambda=4(\Theta-1)+1+\sum_{j} v_{j}
$$

Equation (15) requires the conversion of the reference vector to the $a-b-c$ frame. Variable $j$ corresponds to 1 for phase $A, 2$ for phase $B$ and 3 for phase $C$. After the conversion, variable $v_{x}$ takes the value ' 1 ' if the value in the 
phase $x$ is positive and the value ' 0 ' if the value in the phase $x$ is negative.

Finally, to know how much time the inverter should be placed in in each state is used (16). The $M^{l}$ matrix corresponds to the matrix of the vectors that compose the actual tetrahedron.

$$
\left[\begin{array}{l}
t_{1} \\
t_{2} \\
t_{3}
\end{array}\right]=M^{-1} T\left[\begin{array}{l}
u_{\alpha}{ }^{*} \\
u^{*}{ }^{*} \\
u_{0}{ }^{*}
\end{array}\right]
$$

The switching sequence implemented was the symmetrically generated SVM proposed in [17]. In this sequence the modulation period is divided in two, where half is in the rise part of the triangular carrier and the other half in the fall part of the triangular carrier. The inverter starts in vector zero $\left(\mathrm{V}_{0}\right)$ and ends in the other zero vector $\left(\mathrm{V}_{15}\right)$, this in half the period. The next vector is always the one that changes only the state of one leg of the inverter.

\section{HARDWARE DESCRIPTION}

The hardware used to implement the switching techniques is the same and was adapted to work with the three switching techniques (Fig. 5). The power stage of the Shunt Active Power Filter is implemented with an eight IGBTs inverter with a maximum current of $100 \mathrm{~A}$ and $\mathrm{V}_{\mathrm{CE} 0}=1700 \mathrm{~V}$ The inverter is connected to the grid using $3.5 \mathrm{mH}$ inductors. The DC side is composed by four electrolytic capacitors that combined have $5600 \mu \mathrm{F} / 900 \mathrm{~V}$. All the three techniques were implemented to have a switching frequency of $15 \mathrm{kHz}$. In the case of Periodic-Sampling technique, being this nonfixed switching technique, $15 \mathrm{kHz}$ is the maximum switching frequency.

The digital controller in which the switching techniques were implemented was the TMS320F2812, a 32-bit fixed-point DSP by Texas Instruments.

To provide galvanic isolation from the grid, the connection of the Shunt Active Power Filter to the grid is made using three $230 \mathrm{~V} / 50 \mathrm{~V} 10.5 \mathrm{kVA}$ single-phase transformers. The measuring equipment used to obtain the experimental results were a YOKOGAWA DL708E and a FLUKE 435 Power Quality Analyzer.

\section{EXPERIMENTAL RESULTS}

In order to assess the behavior of the Shunt Active Power Filter with the three switching techniques, were performed tests with three unbalanced $R L$ loads, connected between each phase and the neutral, and a three-phase full-bridge rectifier with a resistive-capacitive load. The value of the resistance placed in the DC side of the rectifier is $12.3 \Omega$. In series with the full-bridge rectifier were placed in the phase A an inductor with $197.3 \mu \mathrm{H}$, in phase $B$ an inductor with $520 \mu \mathrm{H}$, and in phase $C$ an inductor with $246 \mu \mathrm{H}$. These loads were used to test the Shunt Active Power Filter because they emulate a good range of power quality problems related with
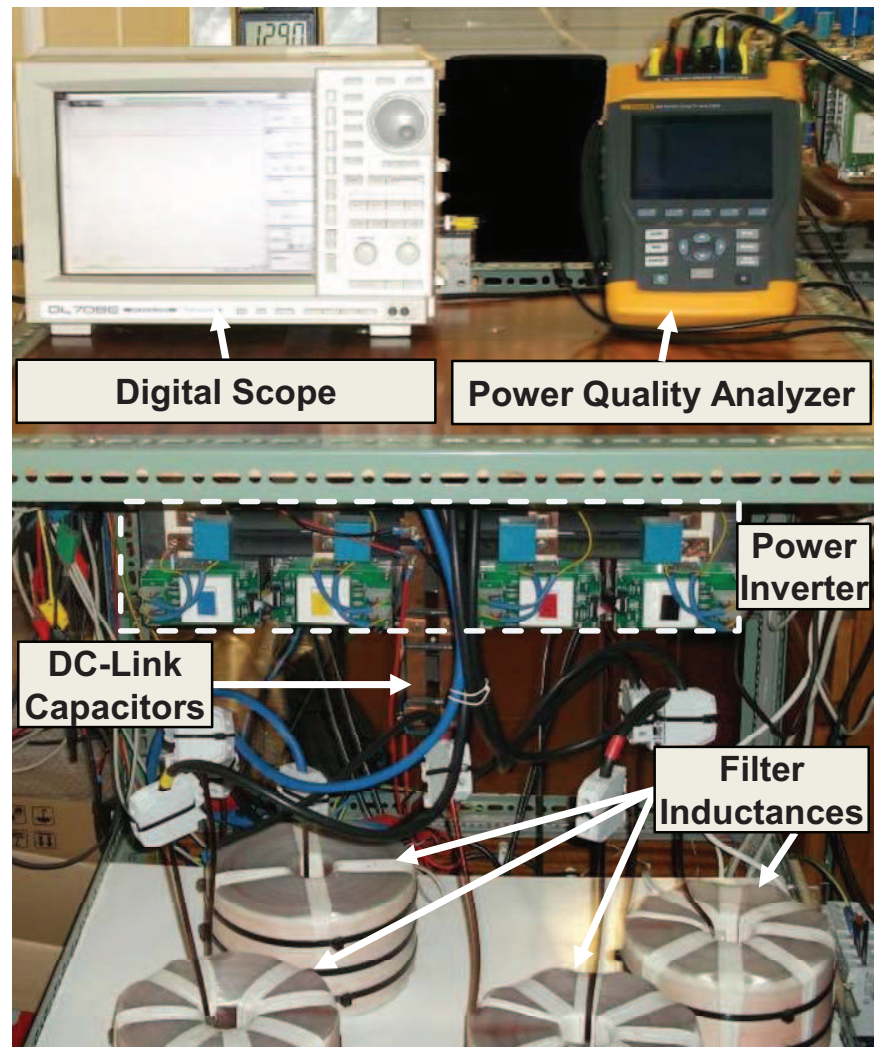

Fig. 5 Shunt Active Power Filter Prototype and measuring set-up.

currents, i.e., power factor, unbalance and harmonics. The currents drawn by the loads from the source, present high values of THD $\%$, up to $49 \%$ (Table I).

The grid voltage and load current waveforms before the compensation are shown in Fig. 6 (a). In this situation, the measured active power was $3.52 \mathrm{~kW}$, the apparent power was $3.91 \mathrm{kVA}$ and the Total Power Factor (TPF) 0,9. In phase $A$ the measured current was $10.1 \mathrm{~A}$, in phase $B 29.5 \mathrm{~A}$, in phase $C 25.2 \mathrm{~A}$ and in the neutral the current is $18.2 \mathrm{~A}$.

With the Shunt Active Power Filter turned-on, the phase currents have similar magnitudes when are used the three switching techniques (23 A), as can be seen in Figure 6.

When compensating using PS switching technique, the measured THDi\% in the current was $4.7 \%$. With TC-PWM the measured THDi\% was $6 \%$ using SVPWM the measured THDi $\%$ was $5.4 \%$.

The experimental results obtained with the Shunt Active Power Filter show that it can successfully compensate current problems, more specifically power factor, unbalanced loads, neutral current and harmonics.

To summarize and allow the comparison of the results, Table I shows the values obtained in the three tests. Analyzing Table I is possible to conclude that using the SVPWM, the current THD\% values are lower than TC-PWM. If we compare the PS technique results, only in the last test the results obtained with SVPWM were greater. These results show that the PS technique adapts better to higher THD\% loads and higher current loads. Considering that the load was the same in all the tests, the measured active power at the 


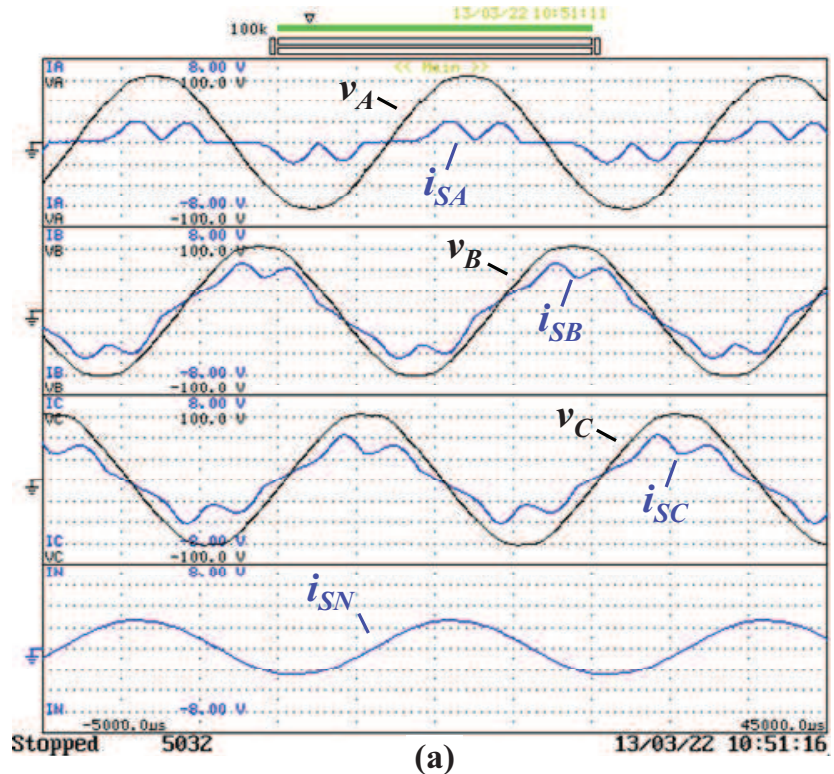

(a)

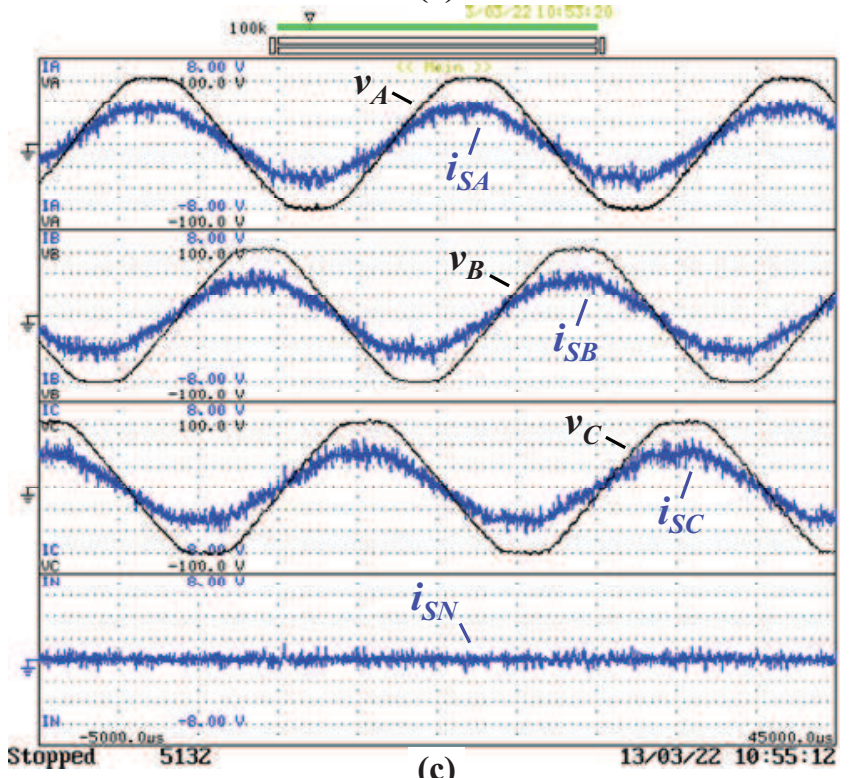

(c)
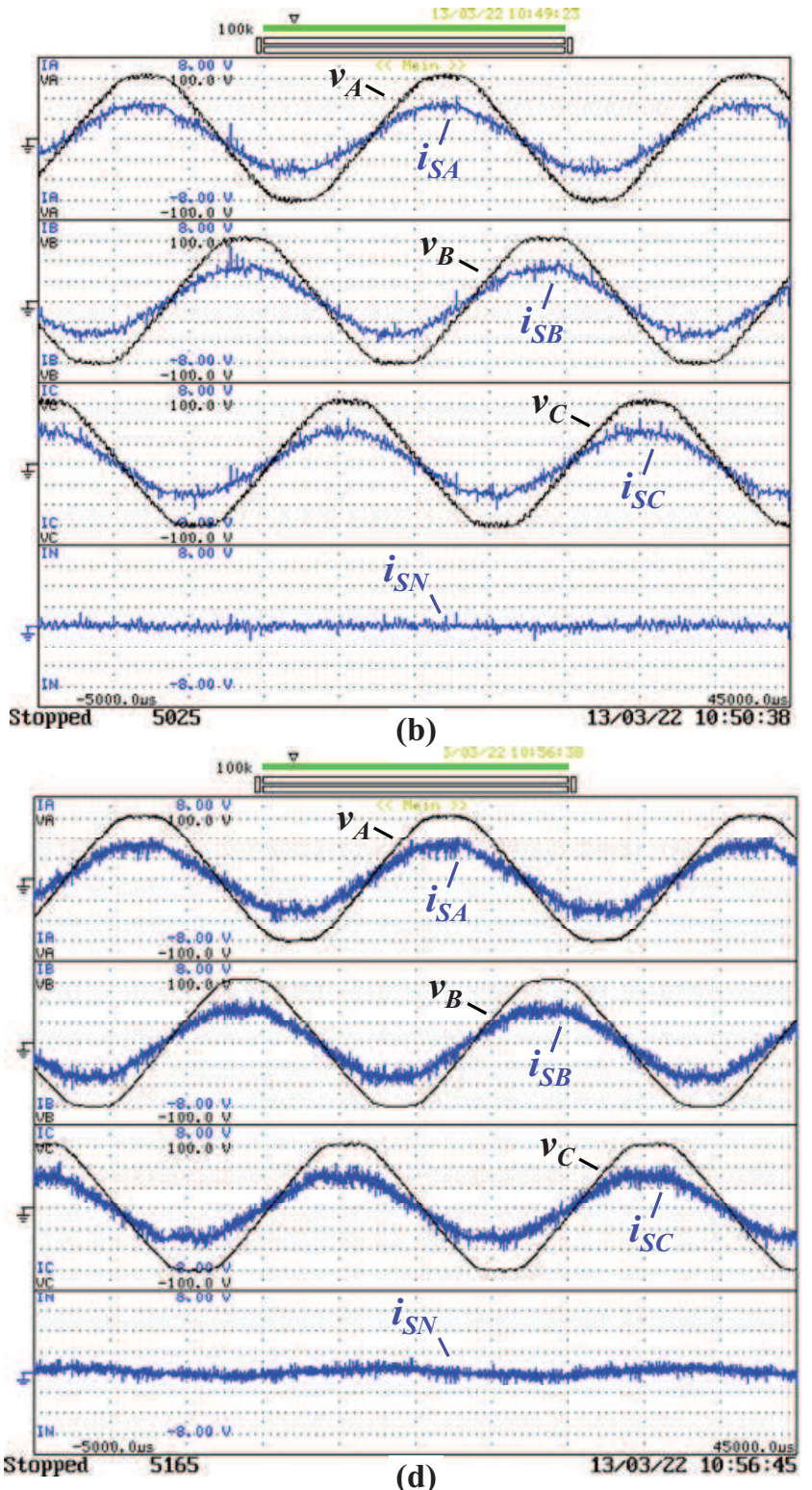

Fig. 6 Experimental results obtained with the developed Shunt Active Power Filter prototype, showing grid voltages, $v_{A}, v_{B}, v_{C}(20 \mathrm{~V} / \mathrm{div})$ and source currents, $i_{S A}, i_{S B}, i_{S C}, i_{S N}(20 \mathrm{~A} / \mathrm{div})$ : (a) Without compensation; (b) With Periodic Sampling (PS) technique; (c) With Triangular Carrier Pulse-Width Modulation (TC PWM) technique; (d) With Space Vector PWM (SVPWM) technique.

source, $P$, can be used to compare the efficiency of the SAPF operating with the three different switching techniques. Since $P$ presents a smaller value with PS, we can conclude that the SAPF is more efficient with this switching technique. Table II summarizes the performance evaluation of the three switching techniques in terms THD\% of the compensated currents, implementation complexity, necessary CPU time and SAPF efficiency.

Analyzing Table II is possible to conclude that, in a comparison between the three switching techniques here evaluated, the PS is the best one, because it is simple to implement, requires low CPU processing time, and with this switching technique the SAPF presents the highest efficiency. Its only disadvantage relatively to the other two techniques is regarding the $\mathrm{THD} \%$ of the compensated currents.
Nevertheless, the difference between the three switching techniques in terms of THD $\%$ is negligible.

The SVPWM technique is the best in terms of THD $\%$ of the compensated currents. In terms of efficiency, because this switching technique defines the state of all the inverter IGBTs as a single block, it presents better SAPF efficiency than the TC-PWM. The main drawback of the SVPWM is the implementation complexity. Also, it needs more processing resources to execute all the tasks. This technique is more appropriate for systems with the requirement of very low $\mathrm{THD} \%$ in the compensated currents.

The TC-PWM technique has an average complexity, and its low performance points are in terms of compensated currents $\mathrm{THD} \%$ and SAPF efficiency. 
TABLE I. RESUlTS IN THE ThreE TESTS

\begin{tabular}{|c|c|c|c|c|c|}
\hline \multicolumn{6}{|c|}{ Shunt Active Power Filter OFF } \\
\hline & Phase A & Phase B & Phase C & Neutral & Total \\
\hline Vrms (V) & 57.14 & 55.39 & 55.63 & -- & -- \\
\hline Arms (A) & 10.1 & 29.5 & 25.2 & 18.2 & -- \\
\hline$\underline{P(k W)}$ & 0.52 & 1.62 & 1.38 & -- & 3.52 \\
\hline$\underline{\mathbf{S}(\mathbf{k V A})}$ & 0.58 & 1.64 & 1.41 & -- & 3.91 \\
\hline Q (kVAr) & 0.07 & 0.06 & 0.02 & -- & 0.16 \\
\hline TPF & 0.89 & 0.99 & 0.98 & -- & 0.9 \\
\hline THDi & $49 \%$ & $13 \%$ & $20 \%$ & -- & -- \\
\hline \multicolumn{6}{|c|}{ Shunt Active Power Filter with with PS } \\
\hline & Phase A & Phase B & Phase C & Neutral & Total \\
\hline Vrms (V) & 55.89 & 56.19 & 55.99 & -- & -- \\
\hline Arms (A) & 22.8 & 22.9 & 22.5 & 2 & -- \\
\hline$\underline{P(k W)}$ & 1.27 & 1.28 & 1.26 & -- & 3.81 \\
\hline S (kVA) & 1.28 & 1.29 & 1.27 & -- & 3.83 \\
\hline$\underline{Q}$ (kVAr) & 0.05 & 0.04 & 0.01 & -- & 0.10 \\
\hline TPF & 1 & 1 & 0.99 & -- & 1 \\
\hline THDi & $5 \%$ & $5 \%$ & $5 \%$ & -- & -- \\
\hline \multicolumn{6}{|c|}{ Shunt Active Power Filter with TC-PWM } \\
\hline & Phase A & Phase B & Phase C & Neutral & Total \\
\hline Vrms (V) & 55.79 & 56.11 & 55.88 & -- & -- \\
\hline Arms (A) & 23.3 & 23.1 & 23.0 & 1.4 & -- \\
\hline$\underline{\mathbf{P}(\mathbf{k W})}$ & 1.29 & 1.29 & 1.28 & -- & 3.87 \\
\hline S (kVA) & 1.29 & 1.3 & 1.28 & -- & 3.87 \\
\hline Q (kVAr) & 0.03 & 0.02 & 0.01 & -- & 0.03 \\
\hline TPF & 1 & 1 & 1 & -- & 1 \\
\hline THDi & $6 \%$ & $6 \%$ & $6 \%$ & -- & -- \\
\hline \multicolumn{6}{|c|}{ Shunt Active Power Filter with SVPWM } \\
\hline & Phase A & Phase B & Phase C & Neutral & Total \\
\hline Vrms (V) & 55.9 & 56.09 & 56.09 & -- & -- \\
\hline Arms (A) & 22.7 & 23.8 & 22.4 & 2.5 & -- \\
\hline$\underline{P}(\mathbf{k W})$ & 1.26 & 1.32 & 1.25 & -- & 3.83 \\
\hline S (kVA) & 1.26 & 1.32 & 1.25 & -- & 3.84 \\
\hline Q (kVAr) & 0.08 & 0.01 & 0.03 & -- & 0.06 \\
\hline TPF & 1 & 1 & 1 & -- & 1 \\
\hline THDi & $5 \%$ & $5 \%$ & $5 \%$ & -- & -- \\
\hline
\end{tabular}

TABLE II. PERFORMANCE COMPARISON

\begin{tabular}{c|c|c|c|c}
\hline $\begin{array}{c}\text { Switching } \\
\text { Technique }\end{array}$ & THD\% & Complexity & $\begin{array}{c}\text { CPU } \\
\text { Time }\end{array}$ & Efficiency \\
\hline PS & middle & better & better & better \\
\hline TC-PWM & worse & middle & middle & worse \\
\hline SVPWM & better & worse & worse & middle \\
\hline
\end{tabular}

\section{CONCLUSIONS}

In this paper was presented the implementation and comparison of three different switching techniques that can be used in Shunt Active Power Filters (SAPFs). This type of equipment is used to compensate various power quality problems, such as power factor, harmonics and unbalanced loads. The studied switching techniques were Periodic-Sampling (PS), Triangular-Carrier PWM (TC-PWM) and Space-Vector PWM (SVPWM). The PS technique is simple to implement and robust, but it does not have a fixed switching frequency. The TC-PWM has fixed switching frequency, but it is difficult to adjust the PI controller gains, especially if the loads change. The SVPWM has similar advantages to the TC-PWM, nevertheless the SVPWM has a superior performance in terms of THD \%. Finally, in terms of CPU Time and implementation complexity, the PS is better than the other two switching techniques.

It is important to note that in the present work the evaluation of switching techniques was made for a SAPF without passive filters (used to mitigate commutation frequencies). These passive filters influence the effectiveness of the SAPFs and can present different behaviors for different switching techniques. The sizing and analysis of passive filters will be addressed in a future work.

\section{ACKNOWLEDGMENT}

This work has been supported by FCT - Fundação para a Ciência e Tecnologia within the Project Scope: Pest-OE/EEI/UI0319/2014.

\section{REFERENCES}

[1] J. G. Pinto, J. L. Afonso, C. Couto, H. Carneiro, and B. Exposto, "Transformerless Series Active Power Filter to Compensate Voltage Disturbances," EPE 2011, pp. 1-8, 2011.

[2] D. Rivas, L. Moran, J. W. Dixon, J. R. Espinoza, "Improving passive filter compensation performance with active techniques," Industrial Electronics, IEEE Trans. on, vol. 50, no. 1, pp. 161-170, 2003.

[3] B. Singh, K. Al-Haddad, and A. Chandra, "A review of active filters for power quality improvement," Industrial Electronics, IEEE Transactions on, vol. 46, no. 5, pp. 960-971, 1999.

[4] J. G. Pinto, P. Neves, D. Goncalves, and J. L. Afonso, "Field results on developed three-phase four-wire Shunt Active Power Filters," in IECON'09. 35th Annual Conference of IEEE, 2009, pp. 480-485.

[5] E. S. Sreeraj, E. K. Prejith, K. Chatterjee, and S. Bandyopadhyay, "An Active Harmonic Filter Based on One-Cycle Control," Industrial Electronics, IEEE Transactions on, vol. 61, no. 8, pp. 3799-3809, 2014.

[6] S. Buso, L. Malesani, and P. Mattavelli, "Comparison of current control techniques for active filter applications," Industrial Electronics, IEEE Transactions on, vol. 45, no. 5, pp. 722-729, 1998.

[7] J. Dixon, S. Tepper, L. Moran, "Practical evaluation of different modulation techniques for current-controlled voltage source inverters," Electric Power Applications, IEE Proceedings -, vol. 143, no. 4, pp. 301-306, 1996.

[8] P. Neves, J. Pinto, R. Pregitzer, L. Monteiro, M. Freitas, J. Afonso, "Experimental Results of a Single-Phase Shunt Active Filter Prototype with Different Switching Techniques," ISIE 2007. IEEE Int. Symposium, 2007, pp. 2499-2504.

[9] B. Exposto, H. Gonçalves, J. G. Pinto, J. L. Afonso, C. Couto, "Three Phase Four Wire Shunt Active Power Filter from Theory to Industrial Facility Tests," in Electrical Power Quality and Utilisation (EPQU), 2011 11th International Conference on, 2011, pp. 1-5.

[10]H. Akagi, Y. Kanazawa, A. Nabae, "Generalized theory of the instantaneous reactive power in three-phase circuits," in IPEC, vol. 83, 1983, pp. $1375-1386$.

[11]M. Aredes and E. H. Watanabe, "New control algorithms for series and shunt three-phase four-wire active power filters," Power Delivery, IEEE Transactions on, vol. 10, no. 3, pp. 1649-1656, 1995.

[12]J. L. Afonso, C. Couto, and J. S. Martins, "Active filters with control based on the pq theory," IEEE Industrial Electronics Society Newsletter, vol. 47, no. 3, pp. 5-10, 2000.

[13]L. F. C. Monteiro, J. L. Afonso, J. G. Pinto, E. Watanabe, M. Aredes, and H. Akagi, "Compensation algorithms based on the pq and CPC theories for switching compensators in micro-grids," in Power Electronics Conference, 2009. COBEP'09. Brazilian, 2009, pp. 32-40.

[14]L. Rolim, D. Costa, M. Aredes, "Analysis and software implementation of a robust synchronizing PLL circuit based on the pq theory," Ind. Elect., IEEE Trans. on, vol. 53, no. 6, pp. 1919-1926, 2006.

[15]M. P. Kazmierkowski and L. Malesani, "Current control techniques for three-phase voltage-source PWM converters: a survey," Industrial Electronics, IEEE Transactions on, vol. 45, no. 5, pp. 691-703, 1998.

[16]R. Zhang, V. Prasad, D. Boroyevich, and F. C. Lee, "Three-dimensional space vector modulation for four-leg voltage-source converters," Power Electronics, IEEE Trans. on, vol. 17, no. 3, pp. 314-326, 2002.

[17]D. O. Neacsu, "Space vector modulation-An introduction," in Proceedings of The 27th Annual Conference of the IEEE Industrial Electronics Society, IECON, vol. 1, no. 1, 2001, pp. 1583-1592. 